\title{
How nursing students perform in problem-based learning tutorials-A South African perspective
}

\author{
Melanie Lack ${ }^{1}$, J udith C. Bruce ${ }^{2}$ \\ 1. Department of Nursing Education, Faculty of Health Sciences, University of the Witwatersrand, Johannesburg, South \\ Africa. 2. Therapeutic Sciences, Faculty of Health Sciences, University of the Witwatersrand, Johannesburg, South Africa.
}

Correspondence: Melanie Lack. Address: Department of Nursing Education, Faculty of Health Sciences, University of the Witwatersrand, Johannesburg, South Africa. Email: melanielack53@gmail.com

Received: January 7, 2014

DOI : 10.5430/jnep.v4n7p156
Accepted: February 26, $2014 \quad$ Online Published: May 19, 2014

URL: http://dx.doi.org/10.5430/jnep.v4n7p156

\section{Abstract}

Background: Problem-based learning tutorials are considered the main vehicle for nursing students to acquire the skills needed to deal with the complexities of nursing practice. How students' perform in these tutorials is an important measure of their learning development and skill acquisition.

Purpose: The purpose of this two phased study was to determine and compare the performance of undergraduate nursing students in Problem-based Learning (PBL) tutorials using a validated evaluation instrument. In Phase-1 of the study the instrument was validated which led to the development of the computer-based: Tutorial Performance Evaluator (TPE). In Phase-2 the performance of undergraduate nursing students in PBL tutorials was assessed and described through the use of this instrument by the students and their facilitators.

Methods: A cross-sectional, comparative design was used employing two sample sets: the first sample consisted of a cross-section of the total population of undergraduate nursing students $(\mathrm{N}=53)$ in their first-year to fourth-year of study in a four year Bachelors degree. The second sample comprised the total population of facilitators $(\mathrm{N}=6)$, who were directly involved in facilitating PBL tutorials. A computer-based TPE with seven main-items (skills) and 34 sub-items was used to elicit data on students' self-assessment and facilitator-assessment of tutorial performance. Mean tutorial performance scores were calculated; correlations were drawn between student and facilitator scores and comparisons were made between the different years of study and within the main items to evaluate progress in skill acquisition.

Results: Major findings included notable differences between facilitator-assessment and self-assessment together with a poor performance in all seven constructs on the evaluation instrument amongst first-year students. There was a significant improvement in the mean tutorial performance score from $27 \%$ in first-year students to $87 \%$ in fourth-year students.

Conclusions: The findings suggest that first-year students struggle with PBL and a recommendation is to consider alternative educational strategies to prepare first year students for PBL.

\section{Key words}

Problem-based learning, Tutorial performance, Student nurses, Assessment 


\section{I ntroduction}

Problem-based Learning (PBL) tutorials are structured in small groups during which students are required to work through a patient problem, presented in a variety of formats. Working in small groups requires a considerable amount of effort and practice; regular practice is therefore assumed to lead to the development of skills and that the more the student rehearses the more competent he/she will become in that skill. Effective work in tutorial groups is essential for the success of PBL. A PBL approach provides students with the ability to become self-directed learners, to problem-solve and develop critical thinking skills, make sound clinical decisions and to acquire the motivation to keep abreast of trends in health and health care. Apart from developing skills to meet their learning needs, immediate and on-going, students also learn valuable skills necessary for their work as professionals. These include team work and communication skills. These skills are particularly relevant in the South African context, where the policy of separate development prevented students from diverse racial and cultural backgrounds to work and learn together. In addition to its educational benefits PBL is thus also an instrument of social reform and reconciliation for selected nursing schools in South Africa.

In the South African context, there are many variables that exist amongst undergraduate nursing students. The majority of the students admitted to nursing programmes are from previously disadvantaged backgrounds, and faced with ethnic diversity and cultural complexities. According to such students are faced with a situation where minimal learning has taken place over many years ${ }^{[1]}$. Furthermore, their cultural circumstances have had a negative impact on their exposure to scientific terminology and their general reading and writing skills are poorly developed. These are students who require a great deal of academic support and already compromised, enter tertiary education and study in the English language, a language that is not their mother tongue and of which many have a less than satisfactory understanding.

To some extent these students are able to converse in English at a social level, but struggle with English at an academic level. Studies conducted on the education of African students show that they lack the experience needed in a Western curriculum ${ }^{[2]}$. This is confirmed, in that students may not always succeed in higher education because they are not fluent in English and this affects their ability to express themselves and communicate effectively ${ }^{[3]}$. The struggle that many of the students face in not being able to express themselves adequately in English is reflected in the following statement: 'It was particularly hard for me as a black woman sitting and understanding the pain of those students going through emotions of not being able to say what you want to say, feelings of being inadequate' ${ }^{[4]}$.

For many of these students grasping the new language of medical sciences in their tertiary studies, becomes the aim of survival, students are required to understand and communicate the medical genre, presenting a language of its own. They show competency in the oral language, but struggle in the reading and written language ${ }^{[5]}$.

Not only is the English language a problem to students in tertiary education, one has to understand the primary and secondary level of education that these students have been subjected to. For twelve years at school students have been indoctrinated in the educational behaviourist theory and moulded in the traditional lecture-based, content-oriented learning background ${ }^{[6]}$. Skills required for a problem-based learning approach such as communication, working within a team, critical thinking, decision-making, problem-solving, self-directed learning and a motivation towards learning are usually not well developed. These skills become a generic outcome to any qualification.

Furthermore one has to take into account the issue of gender equality and the pattern of patriarchy in South African society. South Africans live in a male-dominated society wherein males make the decisions and women have little bargaining power ${ }^{[7]}$. Patriarchy is defined and interpreted by many various angles but the common thread running through all the interpretations is male domination ${ }^{[8]}$. It is seen by some as being rooted in tribal societies and reinforced by cultural values derived from male dominance. Furthermore, patriarchy has penetrated all aspects of human thinking and is perceived as an unchangeable phenomenon as opposed to a socially constructed one. This way of thinking impacts on many areas of social interaction. In PBL tutorial groups, a female student is expected to challenge or argue a point with a peer, to disagree or give a better point of view. If male students are present, they tend to dominate the discussion and female students lack the courage to disagree with them. 
PBL tutorials can improve language skills, develop critical thinking, enhance problem-solving and instil self-confidence, while learning as a group ${ }^{[9]}$. Peer, self-and facilitator assessment feedback thus become important mediators of the group learning process.

In a PBL context, group skills for diverse student groups are particularly important. Successful learning outcomes in PBL are dependant, on effective tutorial group functioning or group performance ${ }^{[10]}$. This is premised on the notion that students possess certain attributes and level of skill necessary for effective functioning within PBL groups or that in the least, these attributes and skills will develop over time. Since many contemporary students come from previously disadvantaged backgrounds and as such, do not possess the requisite skills for group learning it became important to determine whether PBL does in fact contribute to their learning by developing such skills and attributes. There is also agreement among proponents of PBL that such attributes and skills are best evaluated within the context of learning-groups - in this case the PBL tutorial groups.

When a South African specific curriculum for these students is planned, many considerations must be taken into account including the appropriateness of the problem-based approach to learning and teaching. The methodology and statistical analyses used in Phase-1 ${ }^{[11,12]}$ resulted in the validated computer-based Tutorial Performance Evaluator (TPE), which consists of seven (7) main items and 34 sub-items that are weighted and preferentially ranked. In phase-2 the performance of undergraduate nursing students in PBL tutorials was measured and evaluated through the use of this instrument by the students and their facilitators.

This paper reports on the tutorial performance of students at one South African University based in Johannesburg. This University adopted PBL for the delivery of their nursing majors: Comprehensive nursing, Woman's Health and Psychosocial Health. Both formal and informal assessments take place; tutorial performance is informal but routinely evaluated at the close of each tutorial session by both students and facilitators through qualitative comments. Informal feedback on their performance during each session is taken seriously as it helps to build the students' confidence and competence and serves as a primer for the quantitative assessment of their tutorial performance. Formal tutorial performance assessment is an integral part of continuous assessment and makes up between 5\%-15\% of the course mark. Assessment is done by students' and facilitators, annually or bi-annually on a paper-based Tutorial Performance Evaluation Instrument. Facilitators then arrange individual meetings with the students to discuss the self-assessment and the facilitator-assessment scores awarded for each sub-item. An agreed upon score is entered onto the computer-based TPE which then automatically calculates weighted scores for each item and sub-item.

The purpose of the study was to determine the performance of undergraduate nursing students in a 4 year Bachelor's degree programme. Specifically the study addressed the following questions:

- How do students perform in tutorial groups in respect of problem-solving, group contributions,

- communication, critical thinking, personal growth, learning skills and leadership?

- How do students compare in these constructs in the different years of study?

- Is there a difference in how students rate their tutorial performance compared to facilitator ratings?

\section{Methods}

\subsection{Design}

A cross sectional, comparative study design was used to evaluate the performance of undergraduate nursing students in PBL tutorial in all four years of study. Data were collected to allow for comparisons on the learning constructs within and between groups of students in the different years of study and between students' assessments and the facilitators' assessments of tutorial performance. 


\subsection{Participants}

Due to limited numbers the total population of undergraduate Bachelor of Nursing students $(\mathrm{N}=53)$ and PBL facilitators $(\mathrm{N}=6)$ was invited to participate in the study. After reading the study information sheet all facilitators and students gave their consent. The final sample of students was distributed as follows: $28 \%(\mathrm{n}=15)$ were in their first year of study; $40 \%$ $(\mathrm{n}=21)$ were in their second year of study $15 \%(\mathrm{n}=8)$ in their third year and $17 \%(\mathrm{n}=9)$ in their fourth year of study.

\subsection{The instrument}

Evaluating student performance is dependent on assessment criteria from which valid inferences can be made on student learning. Within this study a conceptual framework was used based on the theoretical models of Determination and Quantification of Content Validity; The Subjective Judgement Model. An existing 36 item instrument used to evaluate baccalaureate nursing students' performance in PBL tutorials was presented to a group on experts $(n=5)$ for their subjective judgement of item validity. The 'experts' were selected purposively and were PBL facilitators. The Content Validity Index (CVI) based on the Determination and Quantification of Content Validity was used, items were generated and included over and above the 36 items on the original instrument. Certain items were excluded based on these items not being relevant. The CVI rating scale was used and all items were rated on a scale of 1-4 where 4 represented -very relevant. A Delhi survey using the CVI led to an instrument being developed comprising seven (7) Main-items (constructs) and 34 sub-items variously distributed within each construct. The instrument is referred to as the Tutorial Performance Evaluator (TPE) developed by Lack, Bruce and Becker (2009) Content validity was determined when the total number of 'experts' endorsed each item in the TPE as 'very relevant.' Content validity was established at 1.00. The determination of construct validity was carried out through paired comparisons on visual analogue scales by the 'experts'. The measurements given by the 'experts,' were captured and following statistical analyses, these measurements were converted to ratio scales represented in a percentage. Each item on the TPE now had its own relative weight and could be placed in a hierarchy from highest to lowest percentage. By using the methodological perspectives of the CVI and Subjective judgement the content and construct validity of the instrument was established. The TPE was developed into a computer instrument for accurate calculations multiplying the percentages of each item to obtain a total percentage on the assessment.

The 7 Main- items on the TPE are as follows; Problem-Solving Skills (identify and find solutions to a problem etc.), Contributions to content (integrate ethics, legislation, health service principles and take other disciplines into account) Communication Skills (appropriate verbal and non-verbal skills), Critical Thinking Skills (raises pertinent issue or question, supports an argument with evidence etc.), Learning Skills (use of resources, understand concepts/theories, interpret learning objectives etc.), Personal Growth (being a team member, adheres to ground rules, listens to others, acknowledges contributions from others and manages ground rules etc.) and Leadership (offer facts, suggestions and opinions, drive a process forward, takes decisions, shows assertiveness).

The TPE items are weighted and preferentially ranked and are scored on a 4-point rating scale from 0-3. Mathematical modelling of experts' weighting of the rating scale (Lack et al., 2009) resulted in the following values on the scale: $1=$ $28 \%, 2=69 \%$ and $3=100 \%$. Tutorial performance ratings for each main and sub-item are entered onto the TPE. The calculations are computed automatically by identifying the value of $0,1,2$ or 3 and then converting it into a relative percentage.

\subsection{Procedures}

Ethical clearance was obtained from the Human Research Ethics Committee of the University where the study took place. Students and facilitators respectively were asked, to rate their own and the students' performance in PBL learning groups by completing a paper-based Tutorial Performance Evaluation Instrument (TPEI) which is a replica of the computer based TPE. This was followed by individual meetings between each student and a facilitator to discuss the self-assessment verses facilitator-assessment and to reach consensus on the rating of each item on the TPE. These assessments resulted in three data sets: students' self-assessment ratings $(n=53)$, facilitators' ratings on each student $(n=53)$ and the ratings following 
consensus agreement between the facilitator and the students $(n=53)$. The latter provided the ratings that where entered on the computer-based TPE. A total of 159 assessments were collected and analysed.

\subsection{Data analysis}

The three (3) data sets were analysed using descriptive statistics expressed as the mean, mode, median and standard deviation. Data were further analysed by inferential statistics using a STATA 9 computer statistical package to test for differences and similarities in student scores. Analysis of variance (ANOVA) was used to test the variance in student scores in each year of study and to determine whether the results were statistically significant; significance level was set at 0.05. Skewness and kurtosis were calculated to determine whether each group's data came from a normal distribution. For three of the four student groups skewness was not substantial and ranged between $<1.0$ and $>-1.0$; kurtosis was $<3$. These statistics is a crude indication, with the exception of one data set (second year), that the shape of the distribution is close to normal for a small sample. Other statistical tests used were the Spearman rank-order correlation coefficient, a nonparametric analysis technique to examine the relationships between ranked student scores and facilitator scores. Bartlett's test was used to test for equal variances and Bonferroni's correction test was used to adjust for multiple, smaller comparisons.

\section{Results}

\subsection{Sample characteristics}

Fifty three nursing students $(\mathrm{n}=53)$ and six facilitators $(\mathrm{n}=6)$ completed the TPEI amounting to a $100 \%$ participation rate. Females $(n=43)$ comprised $81 \%$ of the sample and males $(n=10) 19 \%$. All facilitators were female and occupied academic positions at the university. All facilitators were in possession of a recognised qualification in nursing education and were each responsible for a group of students from the first to fourth year of study.

\subsection{Tutorial performance comparisons}

Tutorial performance was evaluated using the ratings of main and sub-items, obtained by consensus between student and facilitator. These scores were entered into the TPE which then computed a weighted percentage for each construct and a composite percentage. First-year students' tutorial performance scores were low ranging from $10 \%$ to $42 \%$ with a mean value of $27 \%(\mathrm{SD}=14.93)$. The majority demonstrated poor critical thinking skills mean of $23 \%(\mathrm{SD}=1.7)$ and problem-solving skills mean of $26.5 \%$ ( $\mathrm{SD}=15.3$ ) respectively. Analysis of variance (ANOVA) showed a significant difference between first and fourth year students in their problem-solving abilities $(\mathrm{df}=3 ; F=18.62 ; p=.0001)$ and critical thinking ( $\mathrm{df}=3 ; F=23.86 ; p=.000)$. Their verbal communication skills and personal growth were marginally better at $35.7 \%(\mathrm{SD}=26.5)$ and $35 \%(\mathrm{SD}=14.8)$ respectively. Students' contribution to discussions in tutorials scored the lowest $(15 \% ; \mathrm{SD}=10.38)$ with a significant difference between the first and fourth year $(\mathrm{df}=3 ; F=41.86 ; p \leq .05)$

By comparison there was a marked improvement in the tutorial performance of second-year students; $81 \%(\mathrm{n}=17)$ achieved above $50 \%$, in a range of $19 \%-88 \%$ producing a mean of $57.4 \%(\mathrm{SD}=22.50)$. The highest score was in verbal communication skills with a mean of $81.3 \%(\mathrm{SD}=25.7)$. Bonferroni's correction test for multiple pair-wise comparison showed that the improvement in communication skills is significant only between the first and second year of study ( $p$ $=.000)$. Students' learning skills were ranked second highest showing a significant improvement on first year scores $(p$ $=.001)$. In aspects of personal growth $76 \%(\mathrm{n}=16)$ showed a significant improvement except between second and third year of study $(p=.760)$. Second year students also assessed their leadership ability as average (58\% showing no significant difference compared to third year of study $(p=1.000)$ Although scores for students contributions to the tutorial group were higher than for first year students, this learning construct was the least well performed by second year students $(55.8 \%$, SD $=19.2)$; on pair-wise comparison the difference was statistically significant $(p=.000)$. Their critical thinking scores were very similar to the third year students (60.0 vs. 58.9$)$ and not statistically significant $(p=.100)$. 
The mean tutorial performance of third year students was $57 \%(\mathrm{SD}=13.8)$ in a range of $38 \%-68 \%$. When comparing to second year scores there was a noticeable difference in the third year students' ability to communicate and contribute to the tutorial group, showing variances of $16.9 \%$ and $12.1 \%$ respectively. However, these differences in communication and contribution to the group were not significant at $p=.514$ and $p=.396$ respectively. With the exception of problem-solving third year students had a lower mean performance score in all other constructs when compared to second year students. The differences in these scores between the second and third year of study were not statistically significant $(p>.05)$.

By comparison the fourth-year students performed better in their PBL tutorials with an overall mean of $87.9 \%$ (SD $=$ 13.70) on the seven (7) constructs with all the students achieving above $70 \%$ in each of the seven constructs. Personal growth and learning skills obtained the highest mean scores of $93.4 \%(\mathrm{SD}=5.3)$ and $91.9 \%(\mathrm{SD}=11.2)$ respectively. Both showed statistically significant differences between the third and fourth year $(p<.05)$. Similarly students' ratings of their leadership skills point to a significant improvement.

Analysis of variance showed that the difference in tutorial performance between the first and final year students was significant for all seven constructs. The mean performance scores and the comparisons according to the TPE constructs and year of study are seen in Table 1 and Table 2 respectively.

Table 1. Mean tutorial performance scores from first to fourth year $(\mathrm{n}=53)$

\begin{tabular}{ll}
\hline Year of study & Mean score $\%$ \\
\hline First year & 27.49 \\
Second year & 64 \\
Third year & 57.11 \\
Fourth year & 87.9 \\
\hline
\end{tabular}

Table 2. Comparison of mean percentages from first-year to fourth-year in Main-items

\begin{tabular}{lllllllll}
\hline \multirow{2}{*}{ Main-item } & \multicolumn{2}{l}{ First year } & \multicolumn{2}{l}{ Second year } & \multicolumn{2}{l}{ Third year } & \multicolumn{2}{c}{ Fourth year } \\
\cline { 2 - 9 } & \% & SD & \% & SD & \% & SD & \% & SD \\
\hline Problem-Solving skills & 26.5 & 15.3 & 57.4 & 22.5 & 59.3 & 10.6 & 83.5 & 19.1 \\
Contributions & 15.3 & 10.3 & 55.8 & 19.2 & 43.7 & 13.2 & 85.4 & 13.9 \\
Communication & 35.7 & 26.5 & 81.3 & 25.7 & 64.4 & 13.9 & 87.4 & 15.2 \\
Critical Thinking skills & 23.5 & 12.7 & 60.6 & 24.7 & 58.9 & 17.4 & 89.6 & 13.4 \\
\hline Learning skills & 26.1 & 13.9 & 67.4 & 20.4 & 59.6 & 13.0 & 91.9 & 11.2 \\
Personal growth & 35.0 & 14.8 & 67.0 & 20.1 & 56.5 & 14.6 & 93.4 & 5.3 \\
\hline Leadership & 30.3 & 10.7 & 58.6 & 24.5 & 57.4 & 13.7 & 84.4 & 17.5 \\
\hline
\end{tabular}

\subsection{Comparison between student self-assessment and facilitator- assessment}

First-year students tended to overrate themselves during self-assessment producing a variance of $27 \%$ between their mean scores $(49.35 \%$; $\mathrm{SD}=10.98)$ and that of the facilitator $(22.27 \% \mathrm{SD}=16.65)$. The greatest difference was seen amongst the male students who on average rated themselves $6 \%$ to $8 \%$ higher to the facilitator rating in comparison to the self-assessment rating of their female counterparts. Spearman's rank correlation $(\mathrm{Rho}=0.3964)$ shows a weak positive correlation between facilitator and student scores, which is not statistically significant $(p=.1435)$.

Second-year students displayed an improved ability in assessing their tutorial performance and produced a smaller variance $(3 \%)$ between their scores and those of the facilitator at the $50^{\text {th }}$ percentile. Their mean scores were $72.16 \%(\mathrm{SD}=$ 
$13.51)$ and $69.46 \%(\mathrm{SD}=21.25)$ respectively. The correlation between these is moderate and statistically significant (Rho $=0.5247 ; p=.0146)$.

In third-year of study there was a 3.5\% difference between the mean students score (61.9) and the facilitator score (58.42). Spearman's rank correlation (Rho $=0.9944)$ shows a strong positive correlation between facilitator and student scores, which is statistically significant $(p=.00001)$.

The fourth-year mean score were almost identical for both students $(87.36 ; \mathrm{SD}=11.3)$ and facilitators $(87.98 ; \mathrm{SD}=10.6)$. These scores showed a strong positive correlation which was statistically significant $(\mathrm{Rho}=0.9406 ; p=.0001)$ (see Table $3)$.

Table 3. Facilitator student mean assessment scores

\begin{tabular}{|c|c|c|c|c|c|c|}
\hline Year & Group & $\%$ & SD & $P$ value & Rho & Significance \\
\hline \multirow{2}{*}{ First year } & Facilitator & 49.8 & 16.6 & \multirow{2}{*}{.1435} & \multirow{2}{*}{0.3964} & \multirow{2}{*}{ Not significant } \\
\hline & Student & 68.9 & 10.9 & & & \\
\hline \multirow{2}{*}{ Second year } & Facilitator & 91 & 21.6 & \multirow{2}{*}{.0146} & \multirow{2}{*}{0.5247} & \multirow{2}{*}{ Significant } \\
\hline & Student & 87.4 & 13.5 & & & \\
\hline \multirow{2}{*}{ Third year } & Facilitator & 69.3 & 11.4 & \multirow{2}{*}{.00001} & \multirow{2}{*}{0.9944} & \multirow{2}{*}{ Significant } \\
\hline & Student & 68.9 & 5.4 & & & \\
\hline \multirow{2}{*}{ Fourth year } & Facilitator & 100 & 10.6 & \multirow{2}{*}{.0001} & \multirow{2}{*}{0.9406} & \multirow{2}{*}{ Significant } \\
\hline & Student & 100 & 11.3 & & & \\
\hline
\end{tabular}

\section{Discussion}

The results indicate that first year students struggle with all aspects of the PBL tutorial. Percentages achieved in the seven constructs featured on the TPE all fell below 50\% with the highest score of 50\% and the lowest score of $9 \%$ achieved by a student in this group. This score indicates a poor baseline performance in PBL tutorials. First-year students showed a poor ability in problem-solving skills with $40 \%$ of the group being unable to identify a problem or work through the problem solving process. Within the group tutorial problem-solving requires communication in questioning discussion. Their communication skills produced a mean score of $35.71 \%$. English not being their mother tongue these students struggled with verbal communication. Students may not always succeed in higher education because they are not fluent in English and this affects their ability to express themselves and communicate effectively ${ }^{[13]}$. Their mean score in critical thinking skills was $23.5 \%$. Certain accreditation bodies internationally require that critical thinking be included in the nursing curricula whilst there is no valid measuring tool for measuring students' critical thinking abilities there is a lack of research to support the assumption that critical thinking can be learned ${ }^{[14]}$. The students were unable to integrate ethics, legislation and health service principles into a discussion and were unable to take other disciplines into account when appropriate. They were also unable to carry out a written self-assessment and tended to overrate themselves.

There was an improvement in all PBL tutorial skills on second year students who obtained a mean score of $64 \%$ on their Tutorial Performance and this result may well be attributed to the PBL approach to teaching and learning. Students showed that they were more familiar with the PBL approach and became more adept at it. There was a substantial improvement in their problem-solving skills achieving a mean score of 57.47\%. Communication skills improved and more discussion took place within the second-year group showing an improved level of confidence in the students' ability to communicate in the English language. However, $23 \%$ of the students displayed minimal communication. Communication skills are an essential element of professionalism and a goal of the PBL model is to provide nursing students with the communication skills needed in healthcare ${ }^{[15]}$. The students showed an improvement in their ability to carry out a self-assessment as there was a strong correlation between student's self-assessment and the facilitator assessment of each student. 
Amongst the third-year students there was a drop in score in all the constructs except problem-solving skills. The mean score achieved was $57.11 \%$. When compared to the second-year students this drop in score could be attributed to the introduction of new subjects such as Midwifery (Women's Health) and Psychosocial Nursing, commencing in third year thereby presenting a further challenge in the form of a 'new language'. Students struggle with English when this language is not their mother tongue but also the new language of medical genre ${ }^{[16]}$. There was an improvement in their problem-solving skills and $88 \%$ of the group were able to identify solutions to the problem. A significant finding was that $12 \%$ of the students showed a limited ability to function within a team. Group interactions generally account for $80 \%$ of the total session time determining deep and collaborative learning as the students strive to develop a critical understanding of the material. It is clear that all interactions except for irrelevant and procedural interactions are conducive to learning ${ }^{[17]}$.

There was an improvement in the tutorial performance achieved by fourth-year students in all seven (7) constructs with a mean score of $87.9 \%$. In the present study the PBL approach to teaching and learning showed advantages to overcome the obstacles students encounter in the skills required to function as a professional e.g. communication skills, problem-solving skills, critical thinking and learning skills amongst others. A cornerstone of PBL is that of self-directed learning (SDL). The benefits of SDL, not only increases the students confidence but serves to develop independent learning skills and a commitment to life-long learning ${ }^{[18]}$. The improvement in the performance of fourth-year students can well be attributed to the development of the SDL skill. In problem-solving skills they achieved a mean score of $83.56 \%$ with a marked improvement in their critical thinking skills with a mean score of $89.66 \%$. Students' development of critical thinking is facilitated or hindered by educational approaches. The effects, of PBL and the lecture approach on the students' critical thinking abilities were compared. These results showed that the significant difference in the development of critical thinking amongst the students from the PBL course occurred as a result of the encouragement of students' active participation in small-group discussions. In a PBL programme, students registered significantly higher critical thinking disposition scores on completion of their training and this remained for two years afterwards although to a lesser degree ${ }^{[19]}$. The didactic content format tends to limit discussion, the use of logic, problem solving and creativity amongst students. Computer technology and 'spoon feeding' also often extinguish students' critical thinking abilities ${ }^{[20]}$. In nursing education, a primary goal is the development of critical thinking through emphasis on process, inquiry and reasoning. Without critical thinking skills it becomes difficult to carry out the problem-solving process effectively ${ }^{[21]}$. Critical thinking using PBL was compared to a conventional approach in an Engineering module and it was found that there was no difference in the two approaches ${ }^{[22]}$.

A major study limitation was that this was not a longitudinal study and one was not following the improvement of each student. As a cross sectional study the performance of each group of students in each year of study was measured and a comparison done. The study showed that there was a vast improvement between first-year and second-year and again between third-year and fourth-year. No studies are available to evaluate the performance of students in PBL tutorials in different years of study. A comparison of results was therefore not able to be made.

\section{Conclusion}

First year students struggle in all aspects of the PBL tutorial and are poor on self-assessments. There was an improvement between first and second year students. Third year students declined in their overall performance when compared with second year. There were significant differences between first and fourth year in all constructs. Good correlation between facilitator and students assessments except third year which had scores lower than the facilitator.

The need for tutorial-based assessment maintains the philosophy of PBL particularly in the ability to develop self-directed learning. Furthermore, it assists the students and the facilitators to identify the areas where academic support is needed. Professional competence requires many skills. Evaluation of these skills provides useful feedback that the students can use to develop future learning habits, self-awareness and self-reflection. It also provides feedback to faculty on the effectiveness of the programme itself. 
The findings from this study show the advantage of the PBL approach to learning particularly amongst the South African undergraduate nursing students. It illustrates the difficulties experienced, particularly amongst the first-year students from an academic and a linguistic point of view and shows the improvement amongst the students when they are evaluated in their fourth year of study.

\section{Acknowledgement}

We would like to acknowledge the statistical contribution of Dr Piet Becker.

\section{References}

[1] Knight A.K. Minimize barriers and Maximize success.

[2] Holtzhausen S.W. Change in Higher Education: The psychological experience of facilitators and coordinators in a resource -based learning course. MSc dissertation. University of the Free State, South Africa, Department of Nursing, 1999.

[3] Foley A. Language policy for higher education in South Africa, South African Journal of Higher Education. 2004 ; $18(1)$ : 57-71. http://dx.doi.org/10.4314/sajhe.v18i1.25428

[4] Lekalakala-Mokgele E. Facilitation as a teaching strategy: The experiences of Facilitators Curationis. 2006; 29(3): 61-69.

[5] Knight A.K. Minimize barriers and Maximize success.

[6] Conrick M. Problem-based learning-managing student transitions, Sydney. Australian problem-based learning network. 1994

[7] Kirkwood F. The Washing Line Project.

[8] Khuele M. Mapping out Patterns of Patriarchy in Social Movements. A Journal for Activists. 2005; $10: 1$.

[9] Choi H. The effects of PBL (Problem-based Learning) on the metacognition, critical thinking and problem-solving process of nursing students. Taehan Kanho Hakhoe Chi. 2004; 34(5): 712-21. PMid:15502436

[10] Savin-Baden M. Problem-based Learning in Higher Education: Untold Stories. The Society for Research in Higher Education and Open University Press 2000.

[11] Bruce J.C. and Lack M. Using Subjective Judgement to Determine the Validity of a Tutorial Performance Evaluation Instrument. Health SA Gesondheid. 2009; 14(1): 1-6.

[12] Lack M, Bruce J.C. and Becker P.J. Weighting of Items in a Tutorial Evaluation Instrument: Statistical Analysis and Results. Health SA Gesondheid. 2009; 14(1): 1-5.

[13] Foley A. Language policy for higher education in South Africa. South African Journal of Higher Education. $2004 ; 18$ (1): 57-71. http://dx.doi.org/10.4314/sajhe.v18i1.25428

[14] Riddell, T. 'Critical Assumptions: Thinking Critically About Critical Thinking', Journal of Nursing Education. 2007; 46(3): 121-126. PMid:17396551

[15] Ustun, Besti. 'Communication Skills Training as Part of a Problem-Based Learning Curriculum'. Nursing Education. 2006; 45(10): 421-424.

[16] Knight A.K. 2004, Minimize barriers and Maximize success.

[17] Visschers-Pleijers, A.J.S.F., Dolmans, D.H.J.M., De Leng, B.A., Wolfhagen, I.H.A.P., Van Der Vleuten, C.P.M. 'Analysis of verbal interactions in tutorial groups: a process study'. Medical Education. 2006; 40: 129-137. PMid:16451240 http://dx.doi.org/10.1111/j.1365-2929.2005.02368.x

[18] Levett-Jones T.L. Self-directed Learning: Implications and Limitations for undergraduate nursing education. Nurse Education Today. 2005; 25: 363-368. PMid:15894411 http://dx.doi.org/10.1016/j.nedt.2005.03.003

[19] Tiwari, A., Lai, P., So, M. and Yuen, K. 'The Comparison of the Effects of Problem-Based Learning and Lecturing on the Development of Students' Critical Thinking', Medical Education. 2006; 40: 547-554. PMid:16700770 http://dx.doi.org/10.1111/j.1365-2929.2006.02481.x

[20] Walsh, C.M. and Seldomridge, L.A. 'Critical Thinking: Back to Square Two', Journal of Nursing Education. 2006; 45(6): 212-219. PMid: 16780009

[21] Duchscher, J.E. 'Critical Thinking: Perceptions of Newly Graduated Female Baccalaureate Nurses', Journal of Nursing Education. 2003; 42(1): 14-25. PMid:12555818

[22] Masek A and Yamin S. The Impact of Instructional Method on Critical Thinking: A Comparison of Problem-Based Learning and Conventional Approach in Engineering Education. International scholarly research network ISRN Education. Volume 2012 Article ID 759241. 